\title{
Water fluxes at an ocean margin in the presence of a submarine canyon
}

\author{
N. Skliris*, J.H. Hecq, S. Djenidi \\ Ecohydrodynamics, GeoHydrodynamics and Environment Research (GHER), University of Liège, Sart Tilman B5, B4000 Liège, Belgium
}

Received 15 January 2001; accepted 17 August 2001

\begin{abstract}
A 3-D, unsteady, nonlinear, high-resolution model is used to estimate shelf/slope exchanges through Calvi Canyon (NW Corsica, Mediterranean Sea) in various regimes of stratification and wind patterns. To evaluate the alongshore and cross-shore fluxes within the canyon area as well as the water exchanges between the canyon and Calvi Bay, volume transports are computed at the sides of two closed, interconnected boxes encompassing the canyon on the shelf and slope domains. Model results show that water transports between Calvi Bay and the open sea are determined by flow modifications in the canyon area. The mean horizontal flow deviates southwestward upstream of the canyon, generating an onshore transport in the western part of Calvi Bay. Within the canyon, the circulation is cyclonic and is responsible for an offshore transport downstream of the canyon and in the eastern part of the bay. The effect of stratification is shown to limit the vertical extent of the influence of canyon topography so that the alongshore flow above the canyon is quasi-undisturbed in strong stratified conditions, resulting in weak cross-shore exchange. Wind events are shown to be responsible for a strong increase of cross-shore transports between the bay and the canyon area. (C) 2002 Elsevier Science B.V. All rights reserved.
\end{abstract}

Keywords: Shelf/slope exchange; Numerical modeling; Submarine canyons; Currents; Northwestern Corsican coast

\section{Introduction}

For some years, the oceanographic community has recognized the environmental significance of shelf/ slope exchange and its important role in global biogeochemical cycling. Field research has shown that submarine canyons, characteristic features of many oceanic shelf-break zones, appear to be preferential pathways for the exchange of water and particles between the coastal area and the open sea (e.g. Durrieu de Madron, 1994; Granata et al., 1999). In most of the coastal re2355 .

* Corresponding author. Tel.: +32-4-366-3647; fax: +32-4-366-

E-mail address: n.skliris@wanadoo.be (N. Skliris). gions, nearshore water is trapped on the shelf by the presence of energetic slope currents, which are in quasigeostrophic balance, following the isobaths, and thus, inhibiting cross-shelf exchanges. Canyons, by bisecting the path of these currents, induce a new dynamic balance that is not geostrophic, leading to significant motions across the slope. As a consequence, an offshore transport of sediments and pollutants produced nearshore takes place, allowing the renewal of coastal water masses. Furthermore, the nonlinear current/canyon interaction and the steep bottom topography generate intense vertical motions. The enhancement of both horizontal and vertical flows in the vicinity of canyons can have important implications on the dynamics of plankton ecosystems and on the carbon cycling in coastal 
regions. The deflection of deeper offshore currents upcanyon may induce a nutrient transport into the euphotic zone on the shelf, leading to the stimulation of biological production (e.g. Freeland and Denman, 1982).

Because of the experimental difficulties encountered in making the time series of in situ measurements over steep topography, observational studies of the 3$\mathrm{D}$ circulation in canyon regions are still relatively scarce. Given the complexity and the highly nonlinear structure of the flow pattern, a numerical modeling approach is necessary to estimate the relative importance of the various physical processes controlling the fluxes of water and particles in the vicinity of these topographic irregularities. Early numerical studies focused on the adjustment processes occurring between the velocity-density fields and the bottom topography, generally considering an idealized geometry/topography of the shelf/canyon areas. Details of the results of previous field and numerical/theoretical studies can be found in Skliris et al. (2001b).

The results are presented from numerical model investigations of current/canyon interactions where a high resolution 3-D model is applied to simulate the real topography of canyon, shelf and nearshore do- mains as well as the complexity of flow dynamics (surface and bottom Ekman layer dynamics, baroclinic effects,...). The site of interest is the Calvi coastal area (Corsica, NW Mediterranean Sea, see Fig. 1) which is under the influence of the Liguro-Provençal Current flowing northeastward along the NW Corsican coast. The region is characterized by a small-scale, deep (500-m mean axial depth), steep-sided (up to $40^{\circ}$ bottom slope) canyon, which has a triangular shape with a mouth approximately $5 \mathrm{~km}$ wide. The canyon head is located in front of Calvi Bay, approximately $4 \mathrm{~km}$ from the Calvi beach. The canyon axis is quasi-perpendicular to the local isobaths, bisecting a narrow and irregular shelf. The main purpose of this study is to quantify the water fluxes between Calvi Bay and the open sea through the canyon area under different stratification and wind regimes.

\section{Numerical model formulation and simulations}

The numerical study is based on the GHER 3-D baroclinic, unsteady, nonlinear primitive equation model using a $k-l$ turbulent closure (e.g. Nihoul and

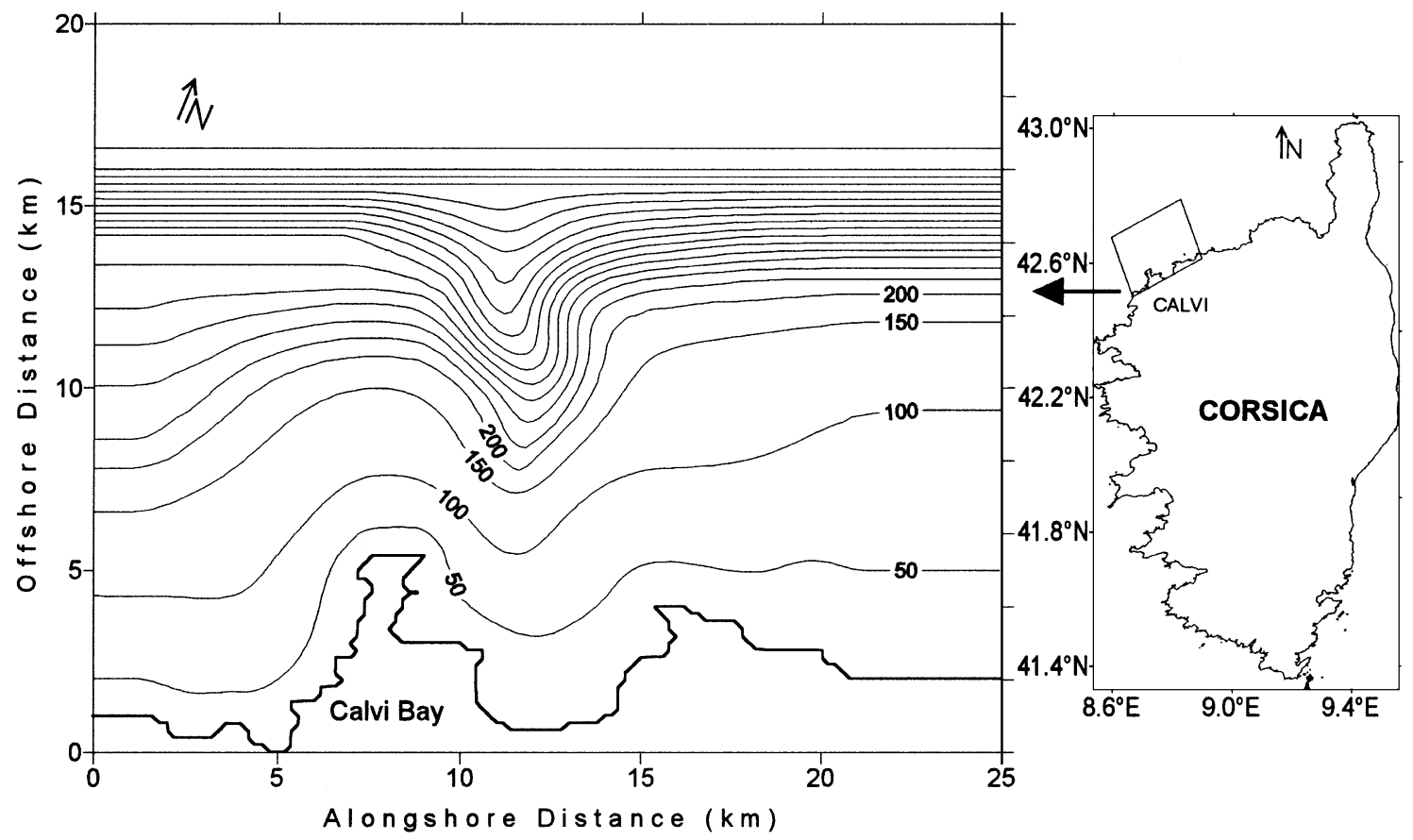

Fig. 1. (a) Bottom topography and location of the Calvi Canyon area (model domain) on the NW Corsican coast. The contour interval for the isobaths is $50 \mathrm{~m}$. 
Djenidi, 1987). A double-sigma transformation is utilized (e.g. Deleersnijder and Beckers, 1992) to represent adequately the baroclinic term in a such highly varying topography. The domain is divided into two superposed interconnected layers, the upper layer's depth following the shelf bathymetry on the shelf and remaining at the maximum shelf's depth $(150 \mathrm{~m})$ in the deep sea. In each layer, the classical sigma transformation is applied.

At the western (upstream) open boundary, the alongshore component of the flow is prescribed to simulate the observed Liguro-Provençal Current, which is based on field measurements off Corsica (Astraldi and Gasparini, 1992). Otherwise, a radiation condition is used at both upstream and downstream open boundaries for all state variables, allowing disturbances originating in the interior of the domain to leave it without disturbing the internal solution (Roed and Cooper, 1987). At the northern open boundary, the cross-shore transport is set to zero while the vertical profile of the current velocity is allowed to develop from the internal solution (gradient-free condition). A free-slip boundary condition is applied at the coast. The computational domain $(25 \times 20 \mathrm{~km})$ is discretized with high horizontal resolution $(200 \times 200 \mathrm{~m})$ in order to represent adequately the topographic gradients in the deep canyon area. The vertical discretization uses $15 \sigma$-levels for the upper layer $(h \leq 150 \mathrm{~m})$ and $15 \sigma$-levels for the deep layer $(h>150 \mathrm{~m})$. Details of the numerical implementation, calibration and validation of the model for this region are thoroughly presented in Skliris et al. (2001b).

With the aim of appraising the influence of stratification, which is a key factor in the current/canyon interaction, the model is applied under weakly and strongly stratified conditions, representative of that observed in the study area, respectively in spring and summer (e.g. Skliris et al., 2001a). For the initial conditions of both stratification cases, a horizontally homogeneous density field is imposed. For the weakly stratified case, one distinguishes three layers with a linear density profile that is characterized by a different buoyancy frequency $N$ : an upper more stratified layer $\left(N=\sim 6 \times 10^{-3} \mathrm{~s}^{-1}\right)$ that is $20 \mathrm{~m}$ deep, a middle less stratified layer $\left(N=\sim 1.5 \times 10^{-3} \mathrm{~s}^{-1}\right)$ with a maximum thickness of $100 \mathrm{~m}$, and a lower very weakly stratified layer $\left(N=\sim 0.5 \times 10^{-3} \mathrm{~s}^{-1}\right)$. For the strongly stratified case, the upper and middle layers are separated by a sharp thermocline $\left(\mathrm{a} 8{ }^{\circ} \mathrm{C}\right.$ difference between 20 and $40 \mathrm{~m}$ ) where $N$ reaches its maximum value $\left(\sim 2.5 \times 10^{-2} \mathrm{~s}^{-1}\right)$. Stratification within the upper $\left(N=\sim 9 \times 10^{-3} \mathrm{~s}^{-1}\right)$ and the middle layers $\left(N=\sim 3.5 \times 10^{-3} \mathrm{~s}^{-1}\right)$ is higher, whereas that of the deepest layer remains invariant (with respect to the weakly stratified case). The initial state of the model is at rest and the numerical runs are carried out for each case of stratification until a quasi-steady state of the flow is reached. Then, numerical runs are performed to evaluate the additional effect of typical wind events often occurring in this area, namely the Libeccio (blowing northeastward) and Tremontane (blowing south-southwestward). For each wind case, a constant speed of $10 \mathrm{~m} \mathrm{~s}^{-1}$ and a 24-h duration are used for the simulations, these values being representative of typical atmospheric conditions in the region (Djenidi, 1985). At the initial time, for each stratification case, the steady state flow obtained from the no-wind simulation is imposed.

To evaluate the alongshore and cross-shore fluxes within the canyon area as well as the water exchange between the canyon and Calvi Bay, volume transports are computed at the sides of two closed, interconnected boxes encompassing the canyon on the shelf and slope domains, respectively (Fig. 2). The alongshore and cross-shore dimensions of the boxes are $8 \times 6 \mathrm{~km}$ and the southern alongshore vertical side of the "shelf box" is located between the canyon head and Calvi Bay. The interface between the two boxes intersects the canyon and shrinks to the 550-m depth at the bottom and is divided into two planes corresponding to the upper 150-m layer and the lower deep layer of the computational domain. The base of the eastern, western and the northern sides of the "slope box" is fixed at the $150-\mathrm{m}$ depth. Concerning the cross-shore volume transports, $V_{1}$ is calculated for the northern side of the "slope box", and $V_{2}$ and $V_{3}$ are calculated for the interface between the two boxes in the upper $150 \mathrm{~m}$ and the deep domain, respectively, while the crossshore volume transport $V_{4}$ is calculated for the southern side of the "shelf box". Alongshore volume transports $U_{1}, U_{3}$, and $U_{2}, U_{4}$ are calculated for the western and eastern cross-shore sides of the boxes, respectively. The vertical transports across the 150-m horizontal planes $W_{1}$ and $W_{2}$ within the boxes are also calculated. For each vertical alongshore and horizontal plane, the total net transport as well as the total positive 
(a)

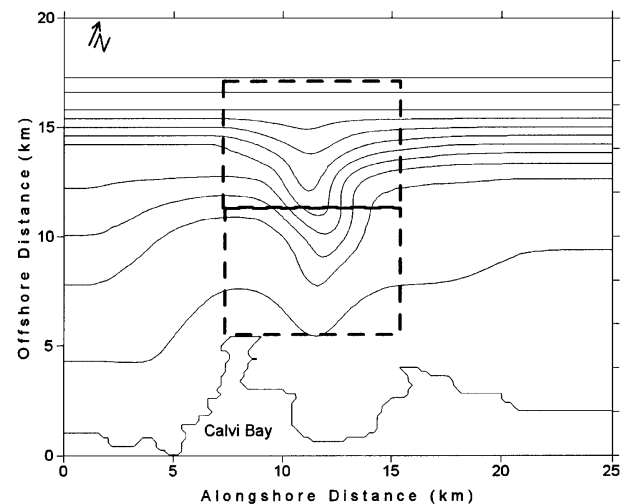

(b)

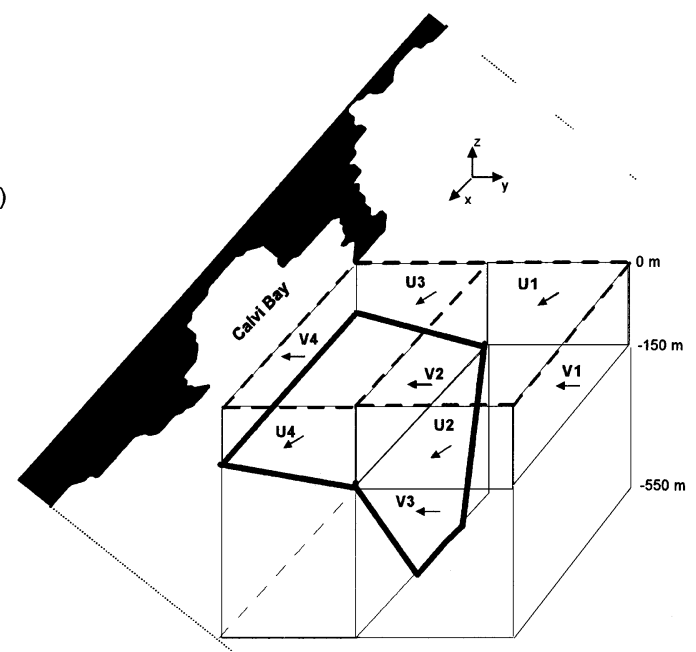

Fig. 2. Schematic representation of the two closed, interconnected boxes where volume transports are computed. (a) Representation of the horizontal upper sides of the boxes at the sea surface (thick dashed lines). (b) Orientation of the boxes relative to Calvi Bay and the schematic representation of the volume transports through the vertical sides of the boxes. Alongshore transports $U$ are calculated along the cross-shore vertical sides of the boxes, whereas crossshore transports $V$ are calculated over the alongshore vertical sides. The thick solid lines represent the bottom slope in each vertical side of the nearshore box while the thick dashed lines represent the upper sides of the boxes at the sea surface as indicated in (a).

and negative transports are computed. Transports are counted positively when directed offshore, eastward or upward and counted negatively when directed onshore, westward or downward. For each case, all volume transports are expressed as a ratio to the total alongshore inflow $\left(U_{1}+U_{3}\right)$.

Further evidence of the circulation is presented here by means of the horizontal current velocity fields. The results of the different model cases may then be compared with the standard (weakly stratified, nowind) case. Current velocity fields that are better than current velocity anomaly fields (with respect to the standard case) are preferred for the presentation of model results since herein, the main purpose is to investigate the flow exchange regime among nearshore, canyon and slope domains.

\section{Results and discussion}

\subsection{Simulations in the negligible wind case}

\subsubsection{Weakly stratified conditions}

Model results demonstrate that water fluxes between Calvi Bay and the open sea are regulated by flow modifications in the vicinity of the canyon. Over the upstream rim of the canyon, the ageostrophic component of the current is enhanced, leading to an acceleration and a meandering of the flow (Fig. 3a). Cross-shelf currents are an order of magnitude larger around the canyon than over the remainder of the shelf break. The nonlinear advection term appears to be the most important term in the momentum equation that is responsible for the difference from the geostrophic balance. The Rossby number Ro (the ratio between the advection over the Coriolis term) evaluated by the model results reaches maximum values of order 1 around the canyon rim, while it presents much lower values $(\sim 0.1)$ in the shelf and slope domains away from the canyon. Upstream of the canyon, a part of the flow deviates southward in shallower depths, creating anticyclonic vorticity and an onshore transport in the western part of the shelf and the bay. Over the canyon, the depth increase results in an increase in cyclonic vorticity. As a consequence, a cyclonic circulation and an offshore transport are generated downstream of the canyon on the eastern part of the shelf and the bay.

Fig. 3. Horizontal distribution of currents for the weakly stratified, no-wind case. Isobaths with a contour interval of $100 \mathrm{~m}$ are plotted with thin solid lines. (a) Mean depth horizontal current velocities $\left(\mathrm{m} \mathrm{s}^{-1}\right)$. (b) Vertical current velocities $\left(\mathrm{m} \mathrm{s}^{-1}\right)$ at $150 \mathrm{~m}$ depth. The thick solid and dashed lines indicate upward and downward flow, respectively. The contour interval is $0.0005 \mathrm{~m} \mathrm{~s}^{-1}$. 
(a)

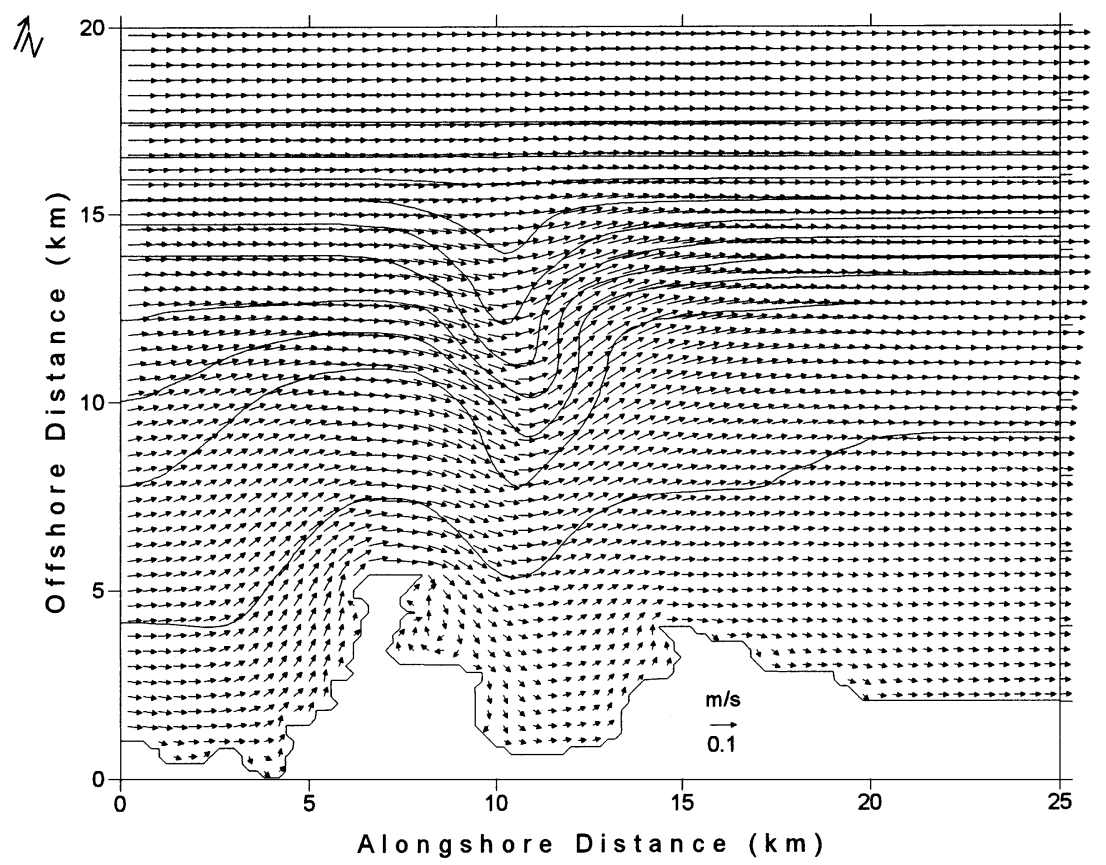

(b)

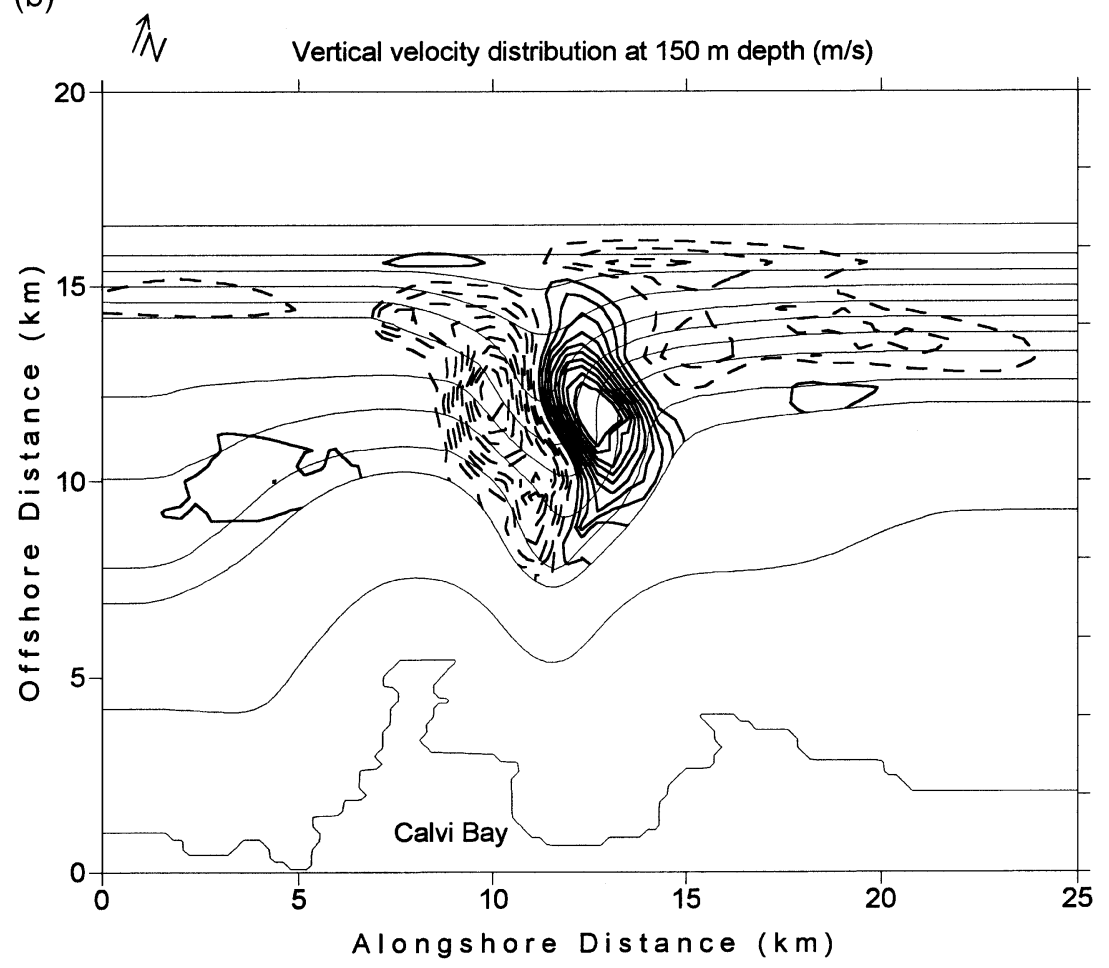


Transport calculations (Table 1) demonstrate the presence of cyclonic circulation in the canyon region. All cross-shore transports are shown to be negative (onshore) upstream of the canyon axis and positive (offshore) downstream of the canyon axis. In the slope domain, the upstream alongshore transport $\left(U_{1}\right)$ is about $11 \%$ larger than the downstream one $\left(U_{2}\right)$, indicating the acceleration of the flow within the canyon. A net offshore transport $\left(V_{1}^{\text {net }}\right)$ occurs which is very small ( $2 \%$ of the total alongshore inflow), consistent with the presence of a slope current in a quasi-geostrophic balance. In the shelf domain, the alongshore volume transport is much larger (about $50 \%)$ upstream $\left(U_{3}\right)$ than downstream of the canyon $\left(U_{4}\right)$, indicating a strong cyclonic turning of the flow

Table 1

Alongshore, cross-shore and vertical volume transports for the six model cases

\begin{tabular}{|c|c|c|c|c|c|c|}
\hline & \multicolumn{2}{|c|}{ No wind } & \multicolumn{2}{|c|}{ NE wind } & \multicolumn{2}{|c|}{ SW wind } \\
\hline & W-S & S-S & W-S & S-S & W-S & S-S \\
\hline$U_{1}$ & 62.5 & 64.9 & 54.2 & 52.2 & 74.3 & 70.0 \\
\hline$U_{2}$ & 69.2 & 67.8 & 56.5 & 54.4 & 84.5 & 78.3 \\
\hline$U_{3}$ & 37.5 & 35.1 & 45.8 & 47.8 & 25.7 & 30.0 \\
\hline$U_{4}$ & 24.7 & 28.9 & 35.5 & 38.9 & 18.0 & 24.3 \\
\hline$V_{1}^{\text {net }}$ & 2.0 & 0.4 & 1.1 & 0.3 & 2.3 & 1.6 \\
\hline$V_{1}^{+}$ & 2.3 & 1.5 & 1.3 & 0.8 & 2.8 & 2.0 \\
\hline$V_{1}^{-}$ & -0.3 & -1.1 & -0.2 & -0.5 & -0.5 & -0.4 \\
\hline$V_{2}^{\text {net }}$ & 9.0 & 3.5 & 3.8 & 2.8 & 12.6 & 10.1 \\
\hline$V_{2}^{+}$ & 18.1 & 8.3 & 10.3 & 6.9 & 26.7 & 21.6 \\
\hline$V_{2}^{-}$ & -9.1 & -4.8 & -6.5 & -4.1 & -14.1 & -11.5 \\
\hline$V_{3}^{\text {net }}$ & 3.3 & 2.4 & 3.9 & 3.0 & 1.2 & 2.0 \\
\hline$V_{3}^{+}$ & 9.4 & 7.5 & 8.6 & 7.1 & 10.0 & 9.7 \\
\hline$V_{3}^{-}$ & -6.1 & -5.1 & -4.7 & -4.1 & -8.8 & -7.7 \\
\hline$V_{4}^{\text {net }}$ & -0.5 & -0.3 & -2.6 & -3.1 & 6.1 & 6.4 \\
\hline$V_{4}^{+}$ & 1.3 & 1.1 & 2.3 & 2.5 & 8.1 & 8.6 \\
\hline$V_{4}^{-}$ & -1.8 & -1.4 & -4.9 & -5.6 & -2.0 & -2.2 \\
\hline$W_{1}{ }^{\text {net }}$ & -0.3 & -0.2 & -0.4 & -0.3 & -0.1 & -0.2 \\
\hline$W_{1}^{+}$ & 11.9 & 9.7 & 10.2 & 9.4 & 12.8 & 12.2 \\
\hline$W_{1}^{-}$ & -12.2 & -9.9 & -10.6 & -9.7 & -12.9 & -12.4 \\
\hline$W_{2}{ }^{\text {net }}$ & -3.3 & -2.4 & -3.9 & -3.0 & -1.2 & -2.0 \\
\hline$W_{2}^{+}$ & 7.1 & 6.1 & 5.2 & 4.9 & 9.6 & 8.2 \\
\hline$W_{2}{ }^{-}$ & -10.4 & -8.5 & -9.1 & -7.9 & -10.8 & -10.2 \\
\hline
\end{tabular}

$U, V$ and $W$ are the alongshore, cross-shore and vertical volume transports, respectively. W-S and S-S denote weakly and strongly stratified conditions, respectively. Superscripts "net", “+”, and " - " denote the net, positive and negative fluxes, respectively. Subscript numbers denote the plane (Fig. 2) for which the transport is calculated. For each model case, all transports are expressed as a percentage of the total alongshore inflow $\left(U_{1}+U_{3}\right)$. Transports are counted positively when directed offshore, eastward or upward and counted negatively when directed onshore, westward or downward. and intense cross-shore water movement within the canyon. Indeed, the flux difference $\left(U_{4}-U_{3}\right)$ is compensated by a net positive (offshore) cross-shore flux in the deep canyon area $\left(V_{2}^{\text {net }}+V_{3}^{\text {net }}\right)$ representing about $12 \%$ of the total alongshore inflow. Both upper and lower layer onshore transports $\left(V_{2}^{-}, V_{3}^{-}\right)$, which occur in the upstream part of the canyon, are smaller than the offshore transports $\left(V_{2}^{+}, V_{3}^{+}\right)$occurring in the downstream part. In contrast, a small net onshore transport occurs near the bay $\left(V_{4}^{\text {net }}\right)$ with upstream negative values higher than downstream positive values. Thus, the steep canyon topography induces an enhancement of the vertical flow, the pattern of which presents an antisymmetrical structure (Fig. 3b). Downwelling is generated on the western side of the canyon (maximum speed of $-7.8 \times 10^{-3} \mathrm{~m} \mathrm{~s}^{-1}$ ), whereas upwelling occurs on the eastern side (maximum speed of $6.4 \times 10^{-3} \mathrm{~m} \mathrm{~s}^{-1}$ ). Both horizontal and vertical velocities are maximum around the canyon rim and minimum near the central axis of the canyon, consistent with a cyclonic circulation in this area. The intensity of upward and downward flows is not uniformly distributed within the canyon (Table 1). In the nearshore canyon area, the downward transport $\left(W_{1}^{-}\right)$ is significantly larger than the upward transport $\left(W_{1}^{+}\right)$, whereas in the outer canyon, the upward transport $\left(W_{2}^{+}\right)$compensates more or less the downward transport $\left(W_{2}^{-}\right)$. This result is probably due to the asymmetry of the canyon geometry that is characterized by a steeper slope on the eastern rim near the canyon mouth. The total downward flow leaving the upper $150-\mathrm{m}$ layer in the western part of the canyon $\left(W_{1}^{-}+W_{2}^{-}\right)$ represents about $23 \%$ of the total alongshore inflow $\left(U_{1}+U_{3}\right)$, whereas the upward flow reaching the upper 150 -m layer in the western part $\left(W_{1}^{+}+W_{2}^{+}\right)$represents $19 \%$ of the inflow, indicating a small but significant net downward motion within the canyon. At the $70-\mathrm{m}$ depth, the simulated temperature (not shown) increased everywhere in the canyon area with respect to the initial temperature (maximum temperature change of about $0.15^{\circ} \mathrm{C}$ ), consistent with a general downwelling there. Just upstream and downstream of the canyon, regions of cooler upwelled water occur (maximum temperature change of about $-0.1{ }^{\circ} \mathrm{C}$ ).

\subsubsection{Strongly stratified conditions}

The effect of the increased stratification is to limit the vertical extent of the influence of the bottom 
topography on the flow pattern over the canyon (Fig. 4). The current within the upper $80 \mathrm{~m}$ crosses the isobaths, ignoring the canyon topography. Below this layer, the circulation becomes cyclonic but its intensity decreases with depth to reach low values in the deep canyon area. Based on the temperature horizontal distribution at $70 \mathrm{~m}$ (Fig. 5), a strong downwelling pool of warmer water occurs within the canyon area (maximum temperature change of about $1.1{ }^{\circ} \mathrm{C}$ ), accompanied by two pools of cooler upwelled water just upstream and downstream of the canyon (maximum temperature change of about $-0.5^{\circ} \mathrm{C}$ ). As a consequence, a strong baroclinic pressure gradient occurs in the canyon region, which is responsible for the enhancement of the cross-isobath flow in the surface layer and of the vertical shear of the currents. Evidence of this circulation pattern is given by the alongshore/cross-shore transport calculations within the canyon (Table 1). Alongshore transports upstream $\left(U_{1}\right.$ and $\left.U_{3}\right)$ and downstream $\left(U_{2}\right.$ and $\left.U_{4}\right)$ of the canyon present much closer values with respect to the weakly stratified case, consistent with the decrease in the amount of cyclonic vorticity within the canyon. Cross-shore transports $\left(V_{2}, V_{3}, V_{4}\right)$ present the same structure with the previous case (with transports upstream of the canyon axis being onshore and downstream of the canyon axis being offshore) but their values are considerably reduced. The total net crossshore transports within the canyon $\left(V_{2}^{\text {net }}+V_{3}^{\text {net }}\right)$ and near the bay $\left(V_{4}^{\text {net }}\right)$ are both reduced to about $40 \%$. The structure of the vertical flow pattern is still antisymmetrical (with downwelling on the upstream side and up- welling on the downstream side of the canyon), but the values of vertical transports $\left(W_{1}^{+}\right.$, $\left.W_{2}^{+}, W_{1}^{-}, W_{2}^{-}\right)$are significantly smaller. The net total vertical (downward) transport $\left(W_{1}^{\text {net }}+W_{2}^{\text {net }}\right)$ is reduced to about $25 \%$.

Model results for the quasi-barotropic and strongly baroclinic regimes over the canyon are consistent with those of other numerical studies (e.g. Klinck, 1996; Allen, 1996) as well as with field observations over a few canyons located on the NW Mediterranean coast such as the Grand-Rhône Canyon (e.g. Durrieu de Madron, 1994) and the Blanes canyon (e.g. Granata et al., 1999). Furthermore, the simulated flow patterns are very similar to those observed in recent laboratory experiments for barotropic and baroclinic flow motions upon a triangular canyon (Didkovskii et al.,
2000). In agreement with this laboratory study, our results show that a part of the alongshore flow turns into the canyon and descends until it reaches the central axis of the canyon. The flow then ascends through the downstream side of the canyon to rejoin the alongshore flow. The structure and intensity of the current velocity field did not change considerably after the flow crossed the canyon.

\subsection{Simulations in the wind-forced cases}

\subsubsection{Northeastward wind}

Simulations performed for a northeastward wind event in weakly stratified conditions show the existence of a marked coastal downwelling. In front of Calvi Bay, wind-induced surface currents are oriented southeastward and bottom currents of lower intensity are oriented northeastward (Fig. 6). The mean flow pattern is qualitatively rather similar to the no-wind case but the circulation on the shelf is clearly reinforced. This is evidenced in the transport calculations (Table 1) where the alongshelf to alongslope transport ratio $\left(U_{1} / U_{3}\right)$ increased with respect to the no-wind case from about 0.6 to 0.85 . The total alongshore inflow $\left(U_{1}+U_{3}\right)$ is about $20 \%$ larger due to the wind forcing that induces a further eastward transport. The total net cross-shore transport in the upper $150 \mathrm{~m}$ $\left(V_{2}^{\text {net }}\right)$ decreased to about $50 \%$ (Table 1 ), indicating that cyclonic vorticity over the canyon is reduced. In the slope domain, changes in the alongshore/crossshore transports are rather small since the wind forcing affects only the upper water column. Both offshore and onshore fluxes in front of Calvi Bay are increased and the net (onshore) transport $\left(V_{3}^{\text {net }}\right)$ is about five times larger than those in the no-wind case, indicating a much more efficient exchange between the bay and the canyon region in this case. Model results also indicate a small but significant decrease of vertical transports both upstream $\left(W_{1}^{-}, W_{2}^{-}\right)$and downstream $\left(W_{1}^{+}, W_{2}^{+}\right)$of the canyon axis. Upwelling velocities are decreased further than downwelling velocities so that the total net vertical (downward) transport $\left(W_{1}^{\text {net }}+W_{2}^{\text {net }}\right)$ is larger than that in the nowind case $(\sim 10 \%)$.

In the case of strongly stratified conditions, a qualitatively similar flow pattern with respect to the previous case (northeastward, weakly stratified conditions) is obtained except for some details. A further 

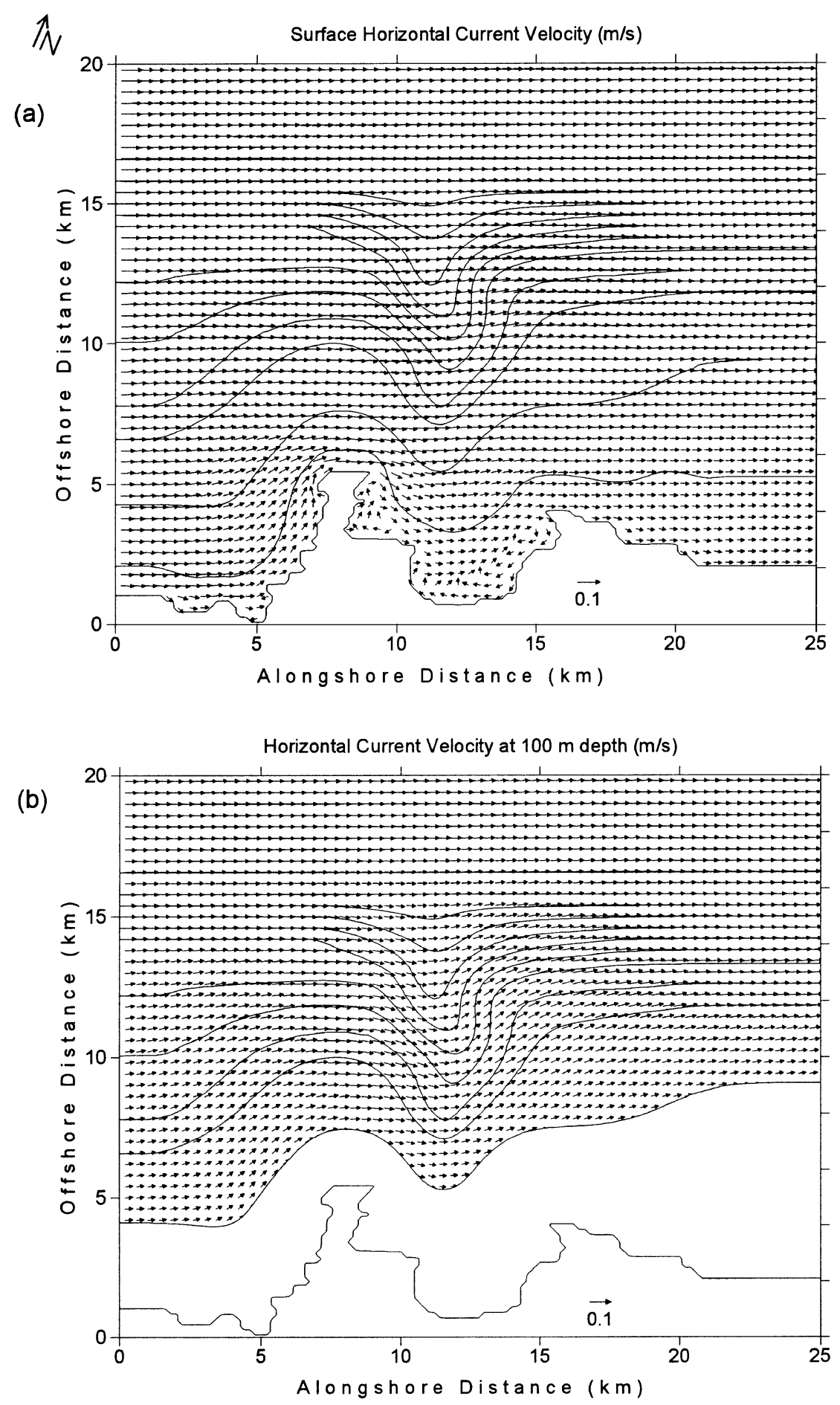

Fig. 4. Horizontal distribution of currents for the strongly stratified, no-wind case. (a) Surface horizontal current velocities (m $\mathrm{s}^{-1}$ ). (b) Horizontal current velocities $\left(\mathrm{m} \mathrm{s}^{-1}\right)$ at the $100-\mathrm{m} \mathrm{depth}$ 


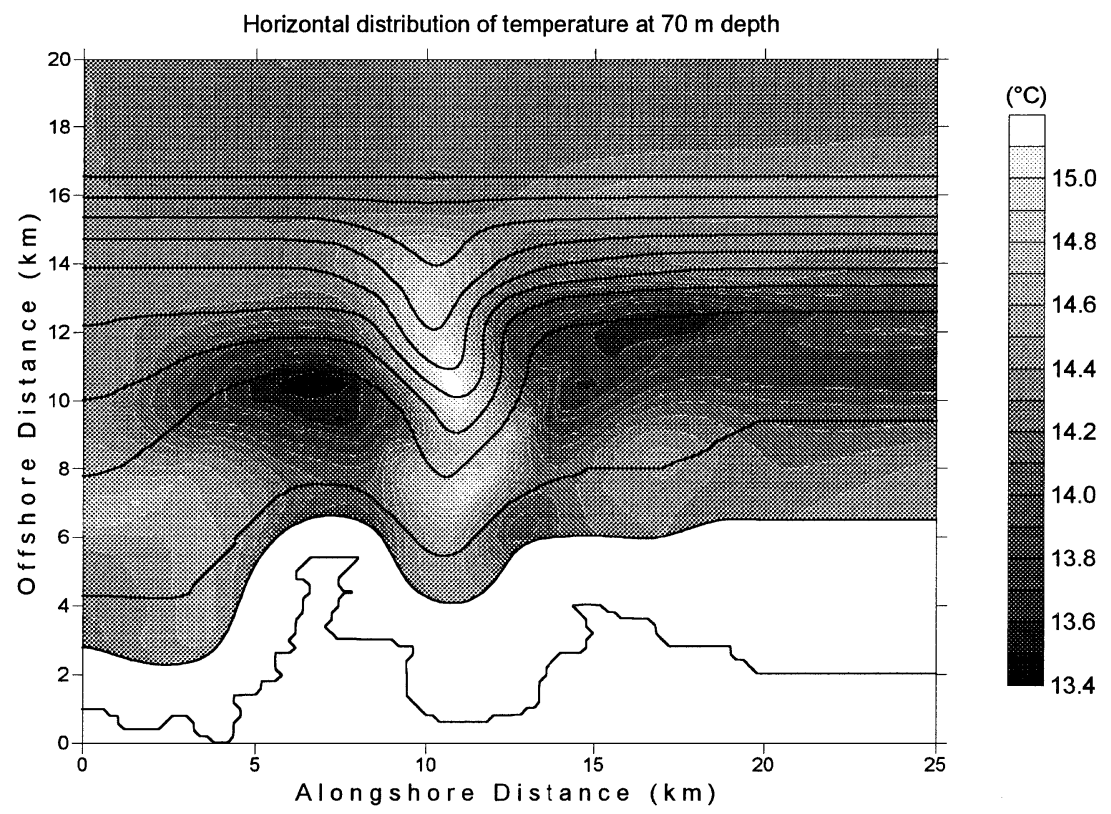

Fig. 5. Horizontal distribution of temperature $\left({ }^{\circ} \mathrm{C}\right)$ at the $70-\mathrm{m}$ depth for the strongly stratified, no-wind case. The initial temperature at this depth is $13.9^{\circ} \mathrm{C}$.

increase of the net onshore transport in front of the bay $\left(V_{4}^{\text {net }}\right)$ occurs. Wind-induced currents trapped by the sharp thermocline are confined within the upper layer, generating a more efficient transport there. On the other hand, the enhanced stratification results in a further decrease of cross-shore $\left(V_{2}, V_{3}\right)$ and vertical transports $\left(W_{1}, W_{2}\right)$ within the canyon.

\subsubsection{South-southwestward wind}

Simulations performed for a south-southwestward wind event in weakly stratified conditions produce a reversal of the flow direction in the nearshore area and the presence of a strong coastal upwelling motion. In front of Calvi Bay, wind-induced surface currents are oriented northwestward, whereas bottom currents are oriented southwestward (Fig. 7) Within the bay, a strong anticyclonic mean circulation is simulated with an offshore flow at the head of the canyon. On the other hand, currents of high intensity (an order of magnitude larger with respect to the no-wind case) enter into the eastern part of the bay. The wind forcing induces a further increase of positive relative vorticity within the canyon, which results in a further enhancement of the cyclonic circulation. The total alongshore inflow $\left(U_{1}+U_{3}\right)$ decreased to about $40 \%$ with respect to the no-wind case since the south-southwestward wind is responsible for a westward transport that is in the opposite direction of the incoming flow. On the other hand, the net cross-shore transport in the upper $150 \mathrm{~m}\left(V_{2}^{\text {net }}\right)$ increased to about $40 \%$ as a consequence of the enhancement of cyclonic vorticity. In front of Calvi Bay, the net cross-shore transport $\left(V_{4}^{\text {net }}\right)$ is now directed offshore and is an order of magnitude larger than that in the no-wind case. This outflow is compensated for by an intense inflow offshore of the eastern edge of the bay. The vertical transports both upstream $\left(W_{1}^{-}, W_{2}^{-}\right)$and downstream $\left(W_{1}^{+}, W_{2}^{+}\right)$of the canyon axis are enhanced as compared with the no-wind case. Upwelling velocities are much more increased than the downwelling velocities so that the total net vertical (downward) transport $\left(W_{1}^{\text {net }}+W_{2}^{\text {net }}\right)$ is reduced with respect to the no-wind case by about $60 \%$.

Strong stratification conditions result in a further increase of the net cross-shore transport near the bay $\left(V_{4}^{\text {net }}\right)$. On the other hand, within the canyon, the increase of cross-shore $\left(V_{2}^{\text {net }}, V_{3}^{\text {net }}\right)$ and vertical $\left(W_{1}\right.$, $W_{2}$ ) transports is smaller than that in the weakly stratified case. 


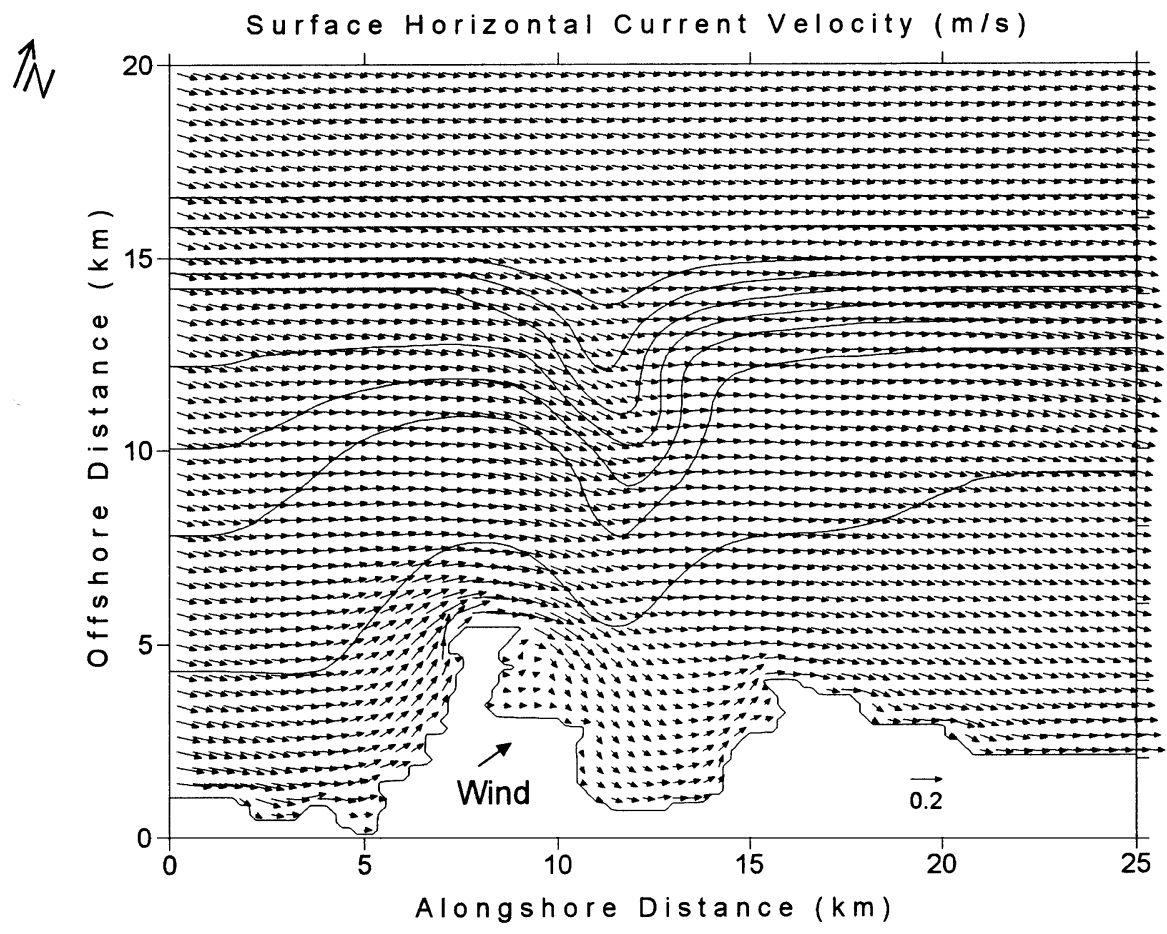

Bottom Horizontal Current Velocity ( $\mathrm{m} / \mathrm{s})$

(b)

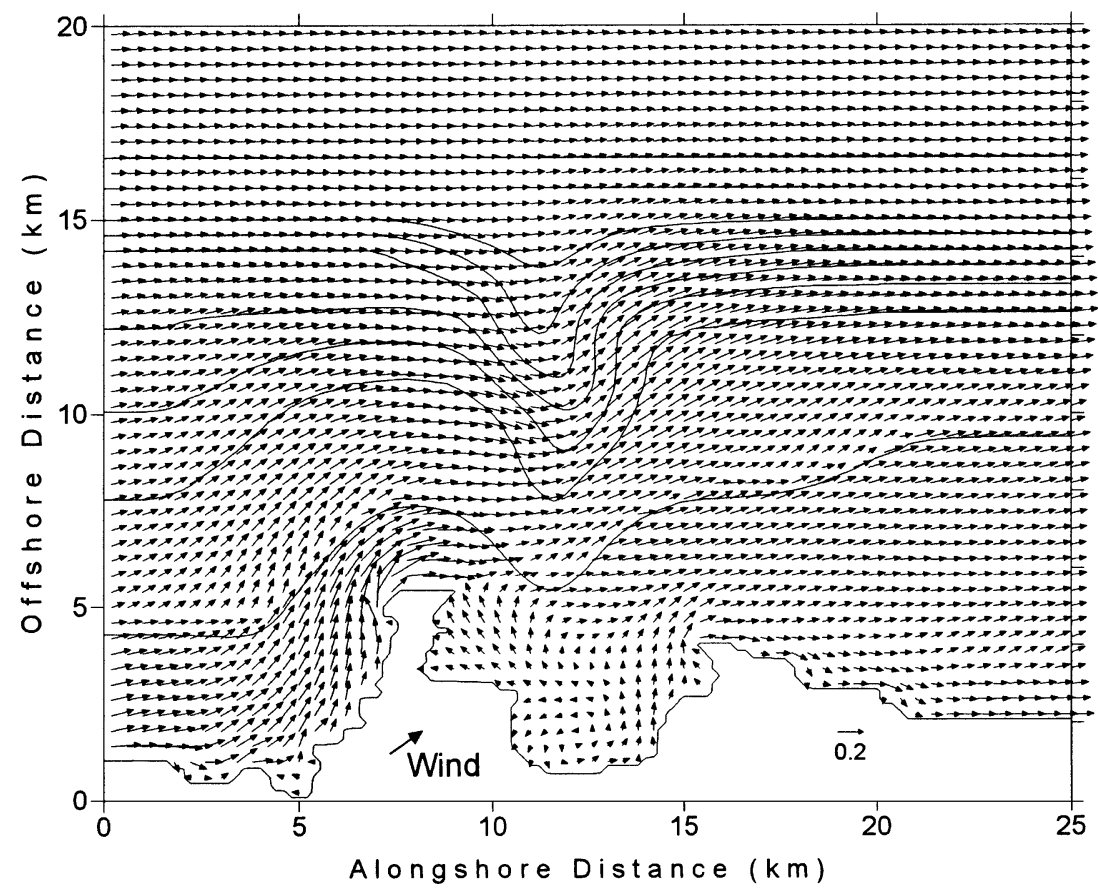

Fig. 6. Horizontal distribution of currents for the weakly stratified, northeastward wind case. (a) Surface horizontal current velocities (m $\mathrm{s}^{-1}$ ) (b) Bottom horizontal current velocities $\left(\mathrm{m} \mathrm{s}^{-1}\right)$. 
(a)

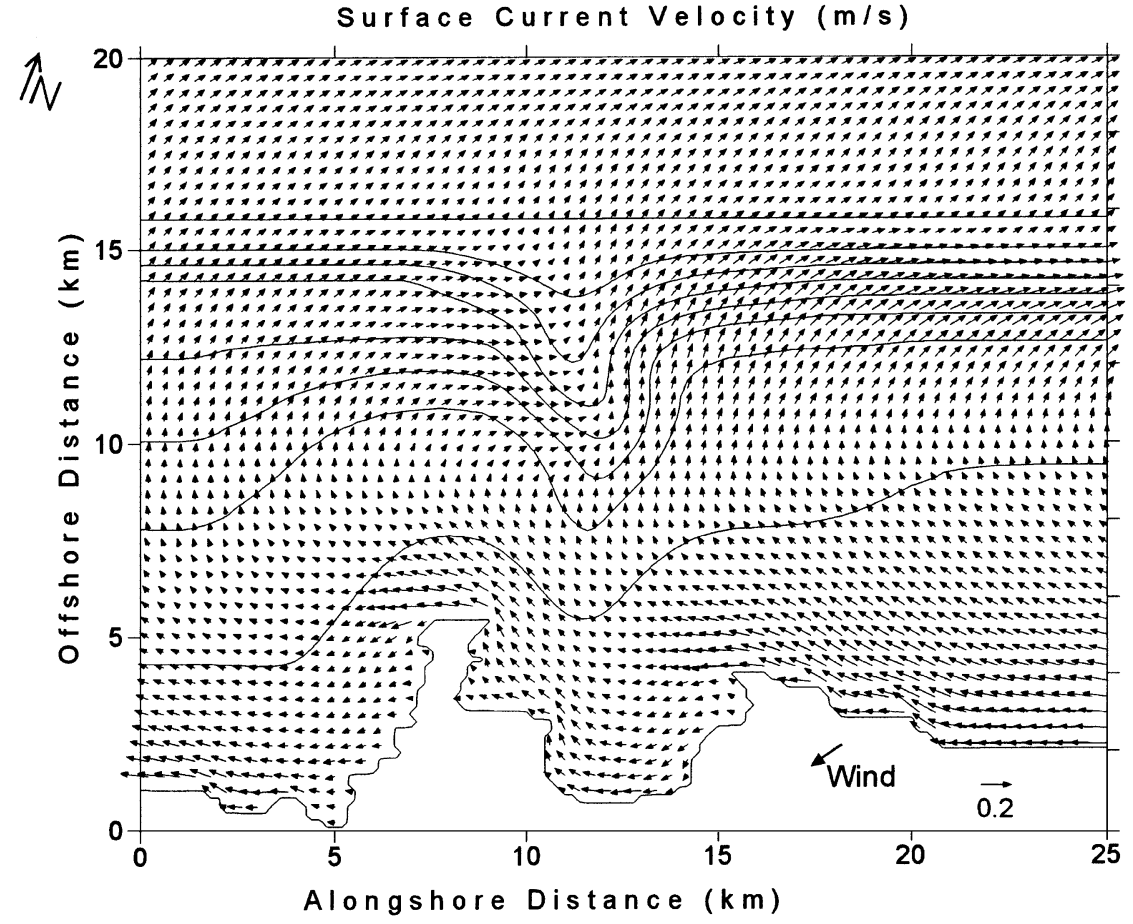

(b)

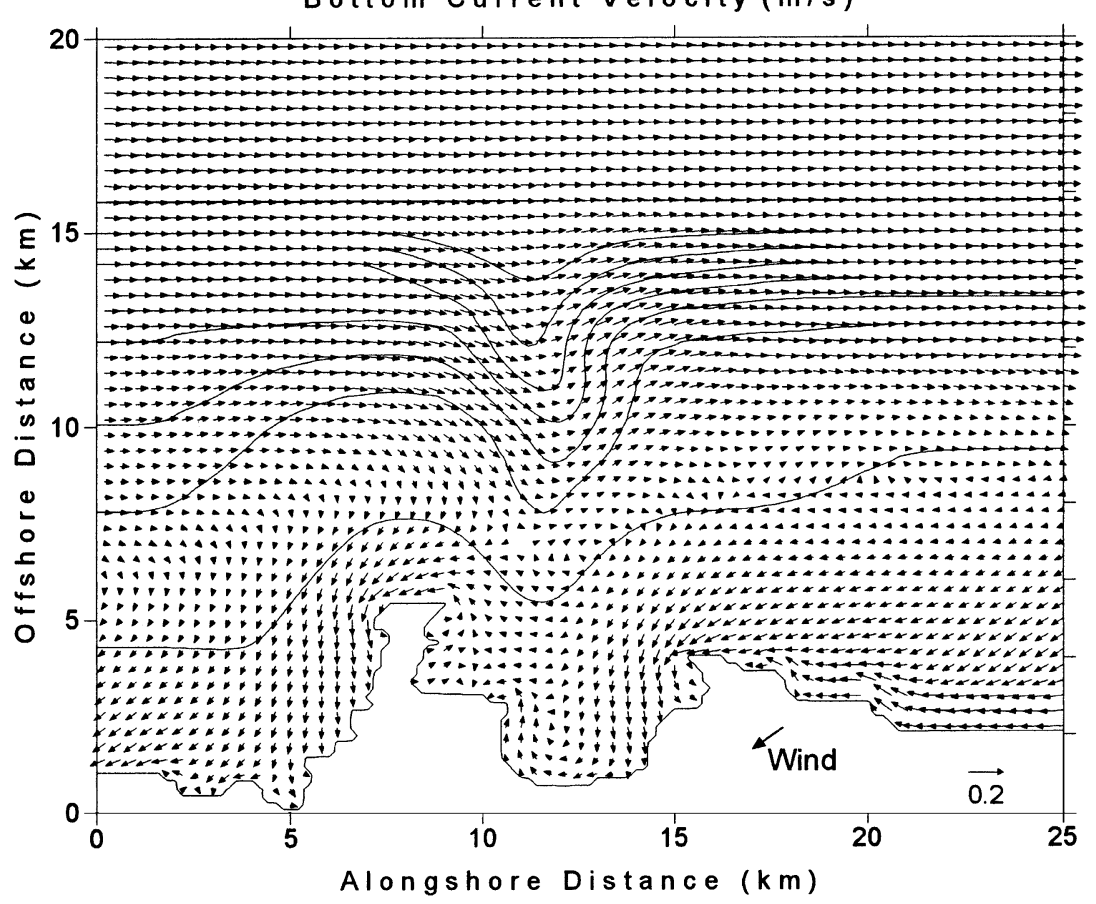

Fig. 7. Horizontal distribution of currents for the weakly stratified, south-southwestward wind case. (a) Surface horizontal current velocities (m $\mathrm{s}^{-1}$ ). (b) Bottom horizontal current velocities $\left(\mathrm{m} \mathrm{s}^{-1}\right.$ ). 


\section{Conclusions}

Water mass exchanges between Calvi Bay and the open sea through a steep-sided canyon have been evaluated by means of a high-resolution 3-D model. The relative importance of different stratification and wind conditions on the exchange regime has been estimated. Results demonstrate that canyon topography is responsible for the enhancement of both crossshore and vertical transports in front of the bay. Onshore transports occur upstream of the canyon axis, whereas offshore transports occur downstream of the canyon axis. The net cross-shore transport in the canyon represents a considerable fraction of the total alongshore inflow (about 12\%) and is six times larger than that occurring further offshore on the slope domain. Near the bay, a small net onshore transport takes place (about $0.5 \%$ of the alongshore inflow). Intense downwelling occurs at the western part of the canyon, whereas upwelling of lower intensity occurs in the eastern part. Total upward and downward transports in the canyon area represent about 19\% and $23 \%$ of the alongshore inflow, respectively.

The effect of stratification is to limit the extent of the topographic influence so that the surface flow crosses the isobaths, ignoring the canyon topography. This flow pattern results in a decrease of about $40 \%$ in the cross-shore exchange through the canyon in both the canyon head and mouth domains.

Strong wind events are responsible for a large increase of cross-shore fluxes through the canyon in front of Calvi Bay. Northeastward winds induce a net onshore transport that is about five times larger than in the no-wind case. South-southwestward winds induce the reversal of the flow and cross-shore transport directions near the coast. As a consequence, a net offshore transport occurs near the bay that is about 10 times larger than that in the no-wind case. Within the canyon region, northeastward (south-southwestward) wind forcing leads to a decrease (increase) of cyclonic vorticity and of the total net cross-shore transport in the upper $150 \mathrm{~m}$ of about $50 \%(40 \%)$. The combined effects of wind forcing and strong stratification result in a further larger increase of cross-shore exchange between the bay and the canyon region.

These predicted features highlight the channeling effect of canyons which act as transition zones of high exchange of water and particles between coastal re- gions and the open sea. On one hand, they may induce an onshore transport of deep water richer in nutrients, stimulating the primary production, and, on the other hand, they may generate an offshore transport of organic particles and pollutants produced nearshore, allowing the renewal of coastal water masses. Furthermore, the low velocity field over the canyon implies a larger residence time of suspended material there. Thus, given the general downwelling pattern within the canyon, one may expect a more efficient transfer of particles to deeper parts of the slope in this region.

\section{Acknowledgements}

This work was accomplished in the framework of projects supported by the "Communauté Française de Belgique" (ARC 97/02.112) and the "Fonds National de la Recherche Scientifique" (FRFC 2.4570.97 and FRFC 2.4609.99). J.-H. Hecq is an FNRS "Chercheur Qualifié".

\section{References}

Allen, S.E., 1996. Topographically generated, subinertial flows within a finite length Canyon. J. Phys. Oceanogr. 26, $1608-$ 1632.

Astraldi, M., Gasparini, G.P., 1992. The seasonal characteristics of the circulation in the north Mediterranean basin and their relationship with the atmospheric-climatic conditions. J. Geophys. Res. 97, 9531-9540.

Deleersnijder, E., Beckers, J.M., 1992. On the use of the $\sigma$ coordinate system in regions of large bathymetric variation. J. Mar. Syst. 3, 381-390.

Didkovskii, V., Semenov, A., Zatzepin, A., 2000. Mesoscale currents upon the smooth sloping bottom and in the presence of ridges and canyons. In: Oceanic Fronts and Related Phenomena, Proceedings of Konstantin Fedorov International Memorial Symposium, Intergovernmental Oceanographic Commission, Workshop Report 159, 89-94.

Djenidi, S., 1985. Observations au large de Calvi en régime d'été. Bull. Soc. R. Sci. Liege 54, 287-300.

Durrieu de Madron, X., 1994. Hydrology and nepheloid structure in the Gran-Rhône canyon. Cont. Shelf Res. 14, 457-477.

Freeland, H.J., Denman, K.L., 1982. A topographically induced upwelling center off southern Vancouver Island. J. Mar. Res. 40, 1069-1093.

Granata, T.C., Vidondo, B., Duarte, C.M., Satta, M.P., Garcia, M., 1999. Hydrodynamics and particle transport associated with a submarine canyon off Blanes (Spain, NW Mediterranean Sea). Cont. Shelf Res. 19, 1249-1263.

Klinck, J.M., 1996. Circulation near submarine canyons: a modelling study. J. Geophys. Res. 101, 1211-1223. 
Nihoul, J.C.J., Djenidi, S., 1987. Perspective in three-dimensional modeling of the marine system. In: Nihoul, J.C.J., Jamart, B. (Eds.), Three-Dimensional Models of Marine and Estuarine Dynamics. Elsevier, Amsterdam, pp. 1-34.

Roed, L.P., Cooper, C.K., 1987. A study of various open boundary conditions for wind-forced barotropic numerical ocean models. In: Nihoul, J.C.J., Jamart, B. (Eds.), Three-Dimensional Models of Marine and Estuarine Dynamics. Elsevier, Amsterdam, pp. $305-336$.
Skliris, N., Elkalay, K., Goffart, A., Frangoulis, C., Hecq, J.H., 2001a. One-dimensional modeling of the plankton ecosystem of the northwestern Corsican coastal area in relation to meteorological constraints. J. Mar. Syst. 27, 337-362.

Skliris, N., Goffart, A., Hecq, J.H., Djenidi, S., 2001b. Shelf-slope exchanges associated with a steep submarine canyon off Calvi (Corsica, NW Mediterranean Sea): a modeling approach. J. Geophys. Res. 106, 19883-19901. 